\title{
Contribuição ao conhecimento dos Hemilophini (Coleoptera, Cerambycidae, Lamiinae), principalmente da Costa Rica
}

\author{
Ubirajara R. Martins ${ }^{1,3} \&$ Maria Helena M. Galileo ${ }^{2,3}$
}

1Museu de Zoologia, Universidade de São Paulo. Caixa Postal 42494, 04218-970 São Paulo-SP, Brasil.
${ }^{2}$ Museu de Ciências Naturais, Fundação Zoobotânica do Rio Grande do Sul. Caixa Postal 1188, 90001-970 Porto Alegre-RS, Brasil.
${ }^{3}$ Bolsista do CNPq.

\begin{abstract}
Contribution to the knowledge of Hemilophini (Coleoptera, Cerambycidae, Lamiinae), primarily from Costa Rica. New records: Sphallonycha irundisa Galileo \& Martins, 2001 for Ecuador; Hilaroleopsis icuapira Martins \& Galileo, 1992, for Costa Rica. New taxa described from Costa Rica: Apebusu gen. nov., type species A. rubriventris sp. nov.; Esamirim gen. nov., type species E. fasciatus sp. nov.; E. carinatus sp. nov.; Kuatinga gen. nov. type species, K. bicolor sp. nov.: Hilaroleopsis theurgus sp. nov.; Abanycha pectoralis sp. nov.; from Panama: Esamirim divisus sp. nov. New combination: Esamirim chionides (Bates,1885) comb. nov. (formerly in Adesmus). Keys to Hemilophini genera with reduced internal tarsal claws and to the species of Esamirim are added.
\end{abstract}

Keywords. Cerambycidae; Hemilophini; Neotropical; new records; new taxa.

Resumo. Novos registros: Sphallonycha irundisa Galileo \& Martins, 2001 para o Ecuador; Hilaroleopsis icuapira Martins \& Galileo, 1992, para a Costa Rica. Novos táxons descritos da Costa Rica: Apebusu gen. nov., espécie-tipo A. rubriventris sp. nov.; Esamirim gen. nov., espécie-tipo E. fasciatus sp. nov.; E. carinatus sp. nov.; Kuatinga gen. nov. espécie-tipo, K.. bicolor sp. nov.: Hilaroleopsis theurgus sp. nov.; Abanycha pectoralis sp. nov.; do Panamá: Esamirim divisus sp. nov. Nova combinação: Esamirim chionides (Bates,1885) comb. nov. (anteriormente em Adesmus). Chaves para gêneros de Hemilophini com garras tarsais internas reduzidas e para as espécies de Esamirim são fornecidas.

Palavras-Chave. Cerambycidae; Hemilophini; Neotropical; novos registros; novos táxons.

Esta contribuição está fundamentada na Coleção Frank T. Hovore, Santa Clarita, California (FTHC) e amplia os conhecimentos, principalmente, da fauna cerambicidológica da Costa Rica. Descrevemos três gêneros, sete espécies novas, propomos uma combinação nova e apresentamos novas ocorrências para duas espécies.

Apresentamos chave para identificar os seis gêneros cujas espécies têm o dente interno das garras tarsais reduzido, isto é, com menos da metade do comprimento do dente externo. Descrevemos também o gênero Esamirim para conter três novas espécies além de $E$. chionides (Bates, 1885). Incluímos ainda duas espécies novas com élitros bicarenados: Hilaroleopsis theurgus sp. nov. de colorido violáceo-azulado e Abanycha pectoralis sp. nov. com curiosa modificação no metasterno dos machos.

As siglas citadas no texto correspondem: Coleção F. T. Hovore, Santa Clarita, California (FTHC); Instituto Nacional de Biodiversidad, Heredia, Costa Rica (INBio); Essig Museum of Entomology, University of California, Berkeley (EMEC); Museu de Ciências Naturais, Fundação Zoobotânica do Rio Grande do Sul, Porto Alegre (MCNZ); Museu de Zoologia, Universidade de São Paulo, São Paulo (MZSP); United States National Museum, Washington (USNM) e Universidad de Costa Rica, San José (UCR).
Chave para os gêneros com dente interno das garras tarsais reduzido

1. Élitros com duas carenas longitudinais: a umeral e outra, pelo menos, na metade apical da declividade lateral

2

Élitros com única carena umeral .......................................... 4

2(1). Garras tarsais com o dente interno largo, curto, de ápice mais arredondado; metasterno sem elevações ......... 3

Garras tarsais bífidas com o dente interno, mais agudo; metasterno com duas gibosidades na área posterior Corcovado Lane

3(2). Lobos oculares inferiores mais longos do que as genas; região posterior do metasterno muito convexa; protórax apenas abaulado lateralmente

Piampatara Martins \& Galileo

Lobos oculares inferiores com menos da metade do comprimento das genas; região posterior do metasterno normal; protórax com gibosidade lateral

. Sphallonycha Bates 
4(1). Lobos oculares inferiores mais curtos do que as genas; élitros regularmente convexos e epipleuras nãoestreitadas; lobos oculares superiores estreitos, distância entre os lobos maior que a largura de um lobo

Lobos oculares inferiores mais longos do que as genas; élitros com dorso aplanado e epipleuras estreitas; lobos oculares superiores largos, distância entre lobos subigual à largura de um lobo

Apebusu gen. nov.

5(4). Élitros com abundantes pêlos longos; ápice dos élitros truncado com espículo no lado externo; antenômeros, a partir do IV, engrossados ......... Kuatinga gen. nov.

Élitros com pêlos longos moderados; ápices dos élitros arredondados em conjunto; antenômeros lineares ..... Esamirim gen. nov.

\section{Sphalonycha irundisa Galileo \& Martins, 2001}

Sphallonycha irundisa Galileo \& Martins, 2001: 61, fig. 9.

Espécie descrita do Brasil, Amazonas, ocorre também no Equador (Napo) onde foi coligida pelo método de pulverização de inseticida no dossel.

Material examinado. BRASIL, Amazonas: Manaus $(1 \mathrm{~km} \mathrm{~W}$ da cascata Tarumã), fêmea, 13.II.1981, C. Young col. (MZSP). EQUADOR, Napo: Reserva Etnica Waoranic $\left(00^{\circ} 39^{\prime} 10^{\prime \prime} \mathrm{S} 76^{\circ} 26^{\prime} \mathrm{W}, 1\right.$ $\mathrm{km}$ sul de Onkone Gare Camp, $220 \mathrm{~m}$ ), macho, 20.I.1994, T. L. Erwin et al. col. "inseticidal fogging of mostly bear green leaves, some with covering of lichenous or bryophytic plants in terre firm forest. At xtrans. 7, $58 \mathrm{~m}$, project MAXUS lot 614" (USNM); ditto, macho, 21.VI.1994, "At 7 x-trans., project MAXUS lot 694" (USNM); ditto, fêmea, 3.VII.1994, "3 x-trans., $51 \mathrm{~m}$, mark, project MAXUS lot 764" (MCNZ); ditto, fêmea, 22.VI.1996, "trans 6, sta 6, project MAXUS, lot 1576" (USNM).

\section{Apebusu gen. nov.}

Etimologia. Tupi, apebusu = achatadão, alusivo à forma achatada dos élitros.

Espécie-tipo: Apebusu rubriventris sp. nov.

Fronte levemente convexa, desarmada nos machos, mais larga do que longa. Mandíbulas com ápice acuminado. Olhos inteiros. Lobos oculares superiores tão próximos entre si quanto a largura de um lobo. Lobos oculares inferiores desenvolvidos, mais longos do que as genas. Antenas mais longas que o corpo, alcançam aproximadamente os ápices dos élitros na ponta do antenômero VII. Escapo subcilíndrico, com comprimento cerca de metade do antenômero III. Flagelômeros não-engrossados. Antenômero III mais longo que o IV; o IV mais longo que o $\mathrm{V}$; os demais progressivamente mais curtos. Franja interna nos antenômeros basais constituída por pêlos longos e esparsos. Protórax mais largo do que longo; lados abaulados, constrições apical e basal da mesma largura. Pronoto sem tubérculos, regularmente convexo. Élitros aplanados no dorso, com carena umeral reta; margens laterais paralelas; extremidades arredondadas. Fêmures sublineares. Ápice dos metafêmures ultrapassa a borda apical do urosternito II. Dente interno das garras tarsais reduzido, tão longo quanto menos da metade do dente externo. Metasterno normal.

\section{Apebusu rubriventris sp. nov.} (Fig. 2)

Cabeça, antenas e pernas, inclusive coxas, pretas. Protórax e face ventral alaranjados. Élitros com declividade lateral preta e região dorsal com tegumento avermelhado coberto por pubescência esbranquiçada e duas faixas longitudinais, estreitas, de tegumento escuro, mais visíveis na metade basal; ambas iniciam-se na base, ao lado do escutelo e depois se bifurcam. Último urosternito com margem apical arredondada. Cabeça com pontos grandes entre os olhos; protórax glabro com pontos esparsos. Metade basal dos élitros com pontos enfileirados; declividade lateral com duas fileiras de pontos junto da carena e pontos de distribuição irregular no terço inferior.

Dimensões, em mm. Comprimento total, 9,1; comprimento do protórax, 1,7; maior largura do protórax, 2,0; comprimento do élitro, 6,5; largura umeral, 2,5.

Material-tipo. Holótipo macho, COSTA RICA, Guanacaste: Estación Mengo (SW side Volcan Cacao, $10^{\circ} 55^{\prime} 43^{\prime \prime} \mathrm{N}, 85^{\circ} 28^{\prime} 10^{\prime \prime} \mathrm{W}$, 1100 m), II.1989, "GNP Biodiversity Survey INBIO CRI001 042371" (INBio). Parátipo: COSTA RICA, Guanacaste: V. Miravalles (Est. Cabro Muco, 1100 m), macho, 3.III - 15.IV.2003, J. Azofeifa, B. Hernández \& J. D. Gutiérrez col., Malaise, \# 6 L N $299769411243 \# 73584$ (MZSP).

Discussão. O colorido corporal de Apebusu rubriventris sp. nov. lembra o de Terpnissa listropterina Bates, 1867 (Elaphidionini, Cerambycinae) e o de Fregolia listropteroides Gounelle, 1911 (Callidiopini, Cerambycinae).

\section{Esamirim gen. n.}

Etimologia. Tupi, esa $=$ olho; mirim $=$ pequeno, alusivo ao tamanho do olho das fêmeas. Masculino.

Espécie-tipo: Esamirim fasciatus sp. nov.

Fronte mais larga do que longa, deprimida longitudinalmente entre os tubérculos anteníferos. Mandíbulas com ápice acuminado. Olhos divididos ou com uma fileira de omatídios entre os lobos. Lobos oculares superiores tão distantes entre si quanto o dobro da largura de um lobo. Lobos oculares inferiores mais curtos do que as genas. Antenas mais longas que o corpo, atingem os ápices dos élitros na ponta do antenômero VIII ou IX. Escapo cilíndrico, com comprimento cerca de metade do antenômero III. Flagelômeros não-engrossados. Antenômero III um terço mais longo ou com quase o dobro do comprimento do IV; o IV um terço mais longo que o V; os demais progressivamente mais curtos. Franja 
interna nos antenômeros basais constituída por pêlos longos e esparsos. Protórax mais largo do que longo; lados abaulados, constrições apical e basal da mesma largura. Pronoto sem tubérculos, regularmente convexo. Carena umeral saliente, reta ou curva. Quando curva, inicia-se no úmero, ascendente até o quarto anterior onde atinge o máximo da altura em relação à epipleura; segue em curva descendente até o terço apical e daí segue reta até o quinto apical onde desaparece. Extremidades arredondadas em conjunto. Ápice dos metafêmures ultrapassa a borda apical do urosternito II. Dente interno das garras tarsais reduzido, tão longo quanto um terço do comprimento do dente externo. Metasterno encurtado.

Chave para as espécies de Esamirim

1. Élitros com manchas ou faixas de pubescência densa branco-amarelada. ... 2

Élitros sem manchas de pubescência esbranquiçada, com os dois terços anteriores pretos e o terço apical alaranjado. (Fig. 3). PANAMÁ ........ E. divisus sp. nov.

2(1). Lados do pronoto com faixas longitudinais de pubescência branca e densa; tíbias amareladas ........ 3

Protórax desprovido de faixas de pubescência branca; tíbias amareladas com anel preto ante-apical. (Fig. 4). COSTA RICA E. fasciatus sp. nov.

3(2). Pequenas dimensões, comprimento $6,8-8,6 \mathrm{~mm}$; faixas de pubescência esbranquiçada no pronoto mais largas que a faixa central de tegumento alaranjado; carena elitral reta; a faixa sutural de pubescência esbranquiçada toca o escutelo. (Fig. 5). COSTA RICA. PANAMÁ ……………….... E. chionides (Bates, 1885)

Dimensões maiores, comprimento $12,8 \mathrm{~mm}$; faixas de pubescência esbranquiçada no pronoto sensivelmente mais estreitas e faixa central de tegumento alaranjado mais larga que as faixas de pubescência branca; carena elitral acentuadamente sinuosa; faixa sutural de pubescência esbranquiçada inicia-se para trás do escutelo. (Fig. 1). COSTA RICA .. E. carinatus $\mathbf{s p . ~ n o v . ~}$

\section{Esamirim chionides (Bates, 1885) comb. nov.} (Fig. 5)

Amphionica chionides Bates, 1885: 430, est. 25, fig. 17.

Adesmus chionides; Auvirillius, 1923: 589 (cat.); Monné, 1995:23 (cat.)

Esta espécie até agora era conhecida do Panamá, Chiriqui (Bugaba).

Material examinado: COSTA RICA, Puntarenas: R.B. Carara (Estación Quebrada Bonita, 50 m), fêmea, VIII-IX.1989, Hanson col. (UCR).

\section{Esamirim carinatus sp. nov.}

(Fig. 1)

Colorido geral alaranjado. Lados do protórax com faixa longitudinal estreita de pubescência branco-amarelada compacta. Cada élitro com cinco manchas de pubescência branco-amarelada, densa: uma alongada, iniciada entre o úmero e o escutelo e prolongada até o quinto anterior; uma longitudinal, que se inicia no sexto anterior, fundida com a sutura e prolonga-se estreitamente sobre a sutura até a mancha apical em forma de "V"; uma dorsal, longitudinal, do terço ao quarto posterior; uma na declividade lateral entre a carena e a margem do sexto anterior ao quinto apical. Carena elitral acentuadamente sinuosa. $\mathrm{Na}$ face ventral, a pubescência branco-amarelada reveste o mesepisterno e o metepisterno; metasterno metafêmures e urosternitos revestidos por pubescência branco-amarelada mais esparsa.

Dimensões em mm. Comprimento total, 12,8; comprimento do protórax, 2,6; maior largura do protórax, 3,2; comprimento do élitro, 9,2; largura umeral, 4,5.

Holótipo fêmea, COSTA RICA, Alajuela: San Ramon de Los Rios (1,5 km NO, Hacienda Nueva Zelandia, $620 \mathrm{~m}), 8-15 . I V .1996$, F. A. Quesada col. "L_N_318100_381900\#7584, INBIO CRI002 400325" (INBio). Parátipo macho, COSTA RICA, Alajuela: R. B. San Ramón $(800 \mathrm{~m}), 2-3 . V I I .1998$, G. Carballo col. (L_N_244100_472100\#50859) (MZSP)

\section{Esamirim fasciatus sp. nov.}

(Fig. 4)

Colorido geral alaranjado. Tegumento preto: terço apical do escapo, antenômeros III-VI menos a base ou a metade basal, antenômeros VII-XI menos a base; anel anteapical nas tíbias. Élitros alaranjados com três faixas longitudinais de pubescência esbranquiçada: uma mais curta no lado interno do úmero; outra, dorsal, da base até além do meio; a terceira mais demarcada, do escutelo ao quinto apical onde se alarga transversalmente em direção à margem; entre estas faixas os élitros são pretos. Olhos inteiros nos machos e divididos nas fêmeas. Lobos oculares superiores tão afastados entre si quanto o diâmetro de um lobo no macho. Nas fêmeas, lobos oculares superiores mais estreitos, tão distantes entre si quanto o triplo da largura de um lobo. Lobos oculares inferiores nos machos pouco mais longos do que as genas; nas fêmeas, notavelmente mais curtos. Protórax dos machos mais abaulados nos lados; nas fêmeas, lados sub-retos. Sutura metasternal mais profunda nos machos do que nas fêmeas. Tarsômero I, nos machos, tão largo quanto o III.

Dimensões, em mm, macho/fêmea respectivamente. Comprimento total, 9,8/10,6; comprimento do protórax, 2,3/2,3; maior largura do protórax, 2,5/2,7; comprimento do élitro, 6,9/ 8,$1 ;$ largura umeral, $3,0 / 3,6$.

Holótipo macho, COSTA RICA, Puntarenas: Golfo Dulce $(3 \mathrm{~km}$ SW Rincón, 10 m), VIII-IX.1990, Hanson col. (INBio). Parátipo fêmea, Cartago: Moravia de Chirripo (1200 m), 2.VI.1987, R. L. Heiterberg (?) col. (MZSP). 


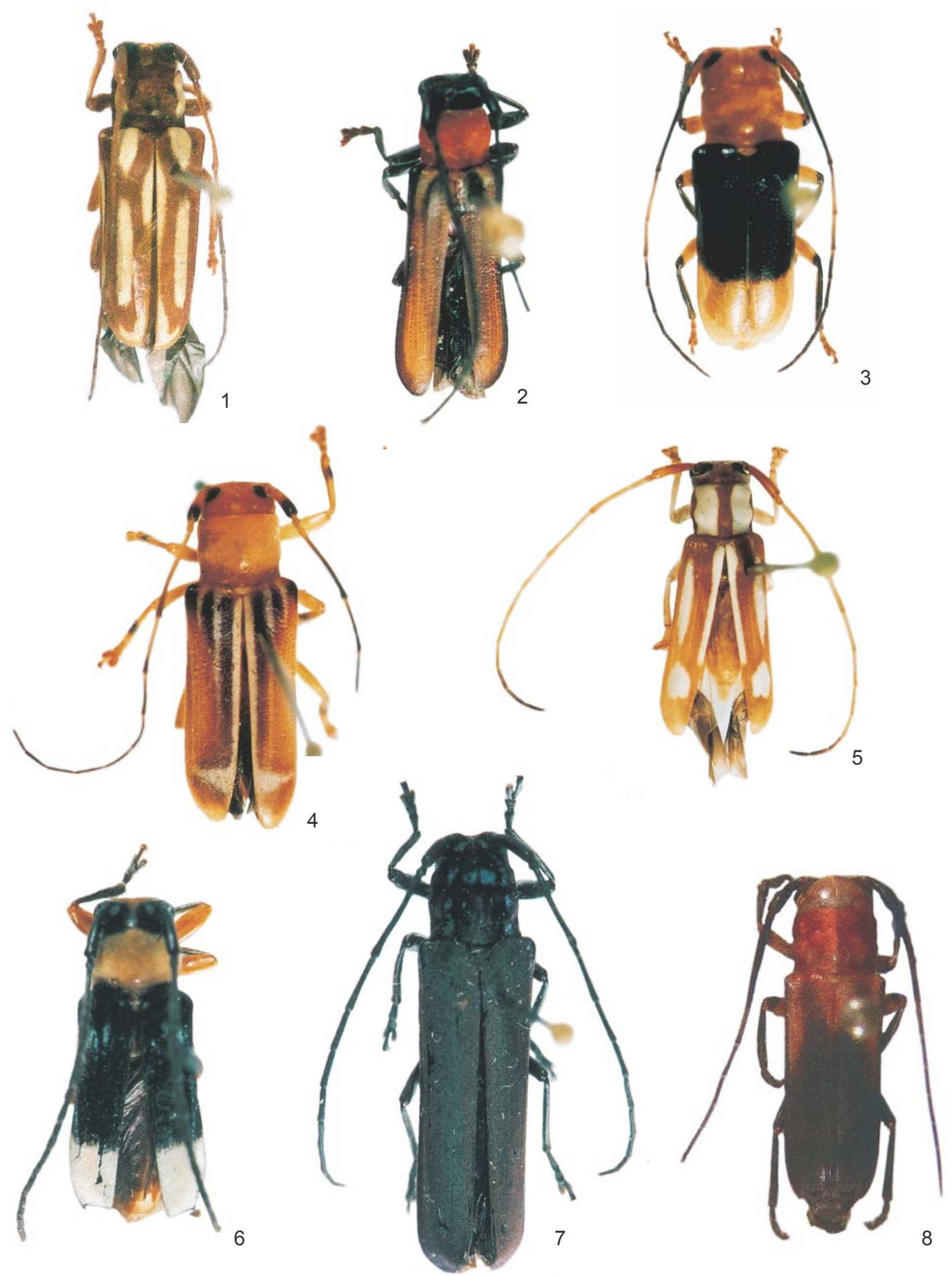

Figs. 1-8. Habitus. 1, Esamirim carinatus sp. nov., holótipo fêmea, comprimento 12,8 mm; 2, Apebusu rubriventris sp. nov., holótipo macho, comprimento 9,1 mm; 3, Esamirim divisus sp. nov., holótipo fêmea, comprimento 9,0 mm; 4, Esamirim fasciatus sp. nov., parátipo fêmea, comprimento 10,6 mm; 5, Esamirim chionides (Bates, 1885), comprimento 8,6 mm; 6, Kuatinga bicolor sp. nov., holótipo macho, comprimento $9,5 \mathrm{~mm} ; \mathbf{7}$, Hilaroleopsis theurgus sp. nov., holótipo macho, comprimento 13,5 mm; 8, Abanycha pectoralis sp. nov., parátipo fêmea, comprimento $12,8 \mathrm{~mm}$. 
Discussão. Esamirim fasciatus sp. nov. apresenta acentuado dimorfismo sexual. Nos machos, os olhos são bem maiores que nas fêmeas; a sutura metasternal é mais profunda e o primeiro tarsômero é consideravelmente mais largo, tão largo quanto o tarsômero III.

\section{Esamirim divisus sp. nov.}

(Fig. 3)

Cabeça alaranjada, nas fêmeas, abaulada no vértice. Olhos divididos. Lobos oculares superiores tão distantes entre si quanto o quádruplo da largura de um lobo. Lobos oculares inferiores com metade do comprimento das genas. Escapo alaranjado no lado interno e preto no lado externo. Pedicelo, antenômero III, lado externo do antenômero IV, antenômero V (menos o ápice), antenômeros VI e VII (menos a base), antenômeros VIII-XI, pretos. Protórax e escutelo alaranjados. Lados do protórax com gibosidade discreta ao nível do terço basal. Élitros com os dois terços anteriores pretos; terço apical amarelado recoberto por pubescência da mesma cor. Fêmures amarelados com pequena porção apical preta. Tíbias pretas no lado externo. Tarsos amarelados. Face ventral amarelada coberta por pubescência esparsa de mesma cor.

Dimensões, em mm. Comprimento total, 9,0; comprimento do protórax, 1,3; maior largura do protórax, 2,5comprimento do élitro, 6,1; largura umeral, 3,2.

Holótipo fêmea, PANAMÁ, Panamá: El Llano (7,5-13 km N), 21-22.V.1994, F. T. Hovore col., "on Cecropia leaves" (EMEC).

\section{Kuatinga gen. nov.}

Etimologia. Tupi, kuá $=$ meio; tinga $=$ branco; alusivo à coloração apical dos élitros. Feminino.

Espécie-tipo: Kuatinga bicolor sp. nov.

Fronte levemente convexa, desarmada, mais larga do que longa. Mandíbulas com ápice acuminado. Olhos inteiros. Lobos oculares superiores tão próximos entre si quanto o dobro da largura de um lobo. Lobos oculares inferiores desenvolvidos, mais longos do que as genas. Antenas mais longas que o corpo, alcançam aproximadamente os ápices dos élitros na ponta do antenômero IX. Escapo subcilíndrico. Antenômero III com aproximadamente 1,4 vezes o comprimento do escapo. Antenômero IV apenas mais curto do que o escapo. Antenômeros, a partir do IV, discretamente engrossados. Franja só no lado interno constituída por pêlos esparsos. Protórax mais largo do que longo; lados abaulados, constrições apical e basal da mesma largura. Pronoto sem tubérculos, regularmente convexo. Úmeros acentuadamente projetados. Élitros com carena umeral reta; margens laterais paralelas; extremidades transversalmente truncadas com espículo externo; abundantes pêlos longos quando vistos de perfil. Fêmures subfusiformes. Ápice dos metafêmures ultrapassam a borda apical do urosternito I. Tarsos com a unha interna soldada à externa até o meio. Metasterno normal.

\section{Kuatinga bicolor sp. nov.}

(Fig. 6)

Fronte avermelhada coberta por pubescência branca que se prolonga posteriormente até o occipício. Regiões atrás dos olhos largamente enegrecidas. Antenas pretas. Protórax com tegumento avermelhado recoberto por densa pubescência esponjosa, esbranquiçada. Lados da base do pronoto estreitamente pretos. Escutelo avermelhado. Élitros pretos com o quarto apical recoberto por pubescência branca; na parte externa do dorso do quarto anterior, pequenas manchas de pubescência branca. Fêmures alaranjados. Tíbias e tarsos pretos. Face ventral alaranjada.

Dimensões, em mm. Comprimento total, 9,5; comprimento do protórax, 2,0; maior largura do protórax, 2,8; comprimento do élitro, 6,9; largura umeral, 3,4. Comprimento: escapo, 1,7; antenômero III, 2,3; antenômero IV, 1,6.

Holótipo macho, COSTA RICA, Guanacaste: Estación Cacao ("SW side Volcan Cacao, 1000-1400 m, 1998-1999", "GNP Biodiv. Survey 232300, 375700" "INBIO CRI 000 103446” (INBio).

\section{Hilaroleopsis icuapira Martins \& Galileo, 1992}

Hilaroleopsis icuapira Martins \& Galileo, 1992: 590, fig. 3; Monné, 1993:21 (cat.).

Discussão. Conhecida apenas do holótipo que foi descrito com base em um exemplar procedente da Costa Rica, mas sem localidade definida.

Material examinado. COSTA RICA, Guanacaste: Rio San Lorenzo (Tierras Morenas, Z. P. Tenorio, 1050 m), macho, 10-20.II.1982, C. Alvarado col. "L-N 287800, 427600" "INBIO CR1000 768081" (INBio).

\section{Hilaroleopsis theurgus sp. nov.}

(Fig. 7)

Etimologia. Latim, theurgus = mágico, alusivo ao colorido corporal .

Tegumento preto. Pubescência branco-azulada iridescente: duas pequenas manchas atrás dos olhos; três manchas pequenas de cada um dos lados do pronoto; mancha diminuta no centro-posterior do pronoto; faixa longitudinal nos lados do protórax. Essas manchas variam na forma conforme a incidência da luz. Élitros, antenas e face ventral do corpo revestidos por pubescência violáceo-metálica uniforme e iridescente que, conforme a incidência da luz, assume brilho azulado. Pubescência branca: região inferior da fronte; prosterno, mesosterno, face anterior dos profêmures, face posterior dos meso- e metafêmures. Lobos oculares superiores tão distantes entre si quanto a largura de um lobo. Nos machos, as antenas atingem o ápice dos élitros na ponta do antenômero $\mathrm{X}$; nas fêmeas, alcançam o quarto apical. Pronoto com gibosidades discretas no meio e duas nos lados. Cada élitro com duas carenas. Extremidades elitrais arredondadas. 
Dimensões em mm, respectivamente macho/fêmea. Comprimento total, 13,0-13,5/15,4; comprimento do protórax, 2,4-2,5/2,8; maior largura do protórax, 2,3-2,7/3,4; comprimento do élitro, 10,1-10,5/11,7; largura umeral, 3,4-3,6/4,3.

Holótipo macho procedente da COSTA RICA, Puntarenas: Monteverde, 19-26.IV.1988, E. Giesbert col. (EMEC). Parátipos: macho com os mesmos dados (MZSP); fêmea, COSTA RICA, Guanacaste: Estación Cacao ("SW side Volcán Cacao, 1000-1400 m"), IV.1988, "GMP Biod. SUR. 323300, 375700" "INBIO CRI000 128438" (INBio).

Discussão. Hilaroleopsis theurgus sp. nov. difere de todas as espécies do gênero pelo colorido uniforme azul-violáceo. Em H. obesus (Bates, 1881) e H. nigerrimus Aurivillius, 1923, os élitros têm colorido uniformemente escuro, mas o pronoto tem faixas de pubescência branca. H. icuapira (MARTins \& Galileo 1992: 590, fig. 3), também conhecida da Costa Rica (sem localidade definida), difere amplamente de $H$. theurgus pelo colorido da cabeça, do protórax e dos élitros.

\section{Abanycha pectoralis sp. nov.} (Fig. 8)

Cabeça alaranjada recoberta por pubescência amarelada; nos machos, com estreita linha longitudinal preta atrás dos lobos oculares. Vértice projetado nas fêmeas. Lobos oculares superiores, nos machos, mais próximos entre si do que a largura de um lobo e, nas fêmeas, tão distantes entre si quanto o dobro da largura de um lobo. Antenas pretas; atingem a ponta dos élitros, nos machos, no antenômero VIII e, nas fêmeas, na ponta do antenômero X. Protórax avermelhado com gibosidade central longitudinal mais aproximada da base. Lados do protórax com gibosidade discreta nos machos e mais acentuada nas fêmeas. Élitros com a metade anterior amarelada e a metade apical preta. Extremidades elitrais com espículo externo. Fêmures amarelados com o ápice preto. Tíbias e tarsos pretos. Meso- e metasterno alaranjados. Metade dorsal dos metepisternos e urosternitos, pretos. Região centro-anterior do metasterno dos machos com duas elevações notáveis, paralelas e curtas, encimadas por pêlos curtos e amareloalaranjados.

Dimensões, em mm, macho/fêmea respectivamente. Comprimento total, 7,8-11,6/7,4-12,8; comprimento do protórax, 1,5-2,4/1,5-2,6; maior largura do protórax, 2,0-3,0/2,1-3,5; comprimento do élitro, 5,7-8,0/5,6-9,0; largura umeral, 2,4-3,5/ $2,4-4,3$.

Holótipo macho, COSTA RICA, Heredia: Estación Biológica La Selva $\left(10^{\circ} 26^{\prime} \mathrm{N} 84^{\circ} 01^{\prime} \mathrm{W}, 50-150 \mathrm{~m}\right)$, VIII-IX.1998, L.M. LaPierre col. (INBio). Parátipos: ditto, 2 machos, 30.VIII.1998, L.M. LaPierre col. (MZSP, FTHC); ditto, 2 fêmeas, VIII.1998, L.M. LaPierre col. (MZSP, FTHC); ditto, 2 fêmeas, IX.1998, L.M. LaPierre col. (FTHC, INBio); ditto, (3 km S de Puerto Viejo), macho, 1.VI.1993, "bosque primario", sem nome do coletor (MCNZ).

Agradecimentos. A Frank T. Hovore pela remessa de relevante material para estudo; a Antonio Santos Silva e Rafael dos Santos Araújo pela execução das fotografias.

\section{REFERÊNCIAS}

Aurivillius, C. 1923. Coleopterorum Catalogus, pars 74, Cerambycidae: Lamiinae. Berlin, W. Junk, p. 323-704.

Bates, H. W. 1885. Biologia Centrali-Americana, Insecta, Coleoptera, suppl. to Longicornia. London, 5: 249-436, est. 1724.

Galileo, M. H. M. \& U. R. Martins, 1999. O gênero Adesmus (Coleoptera, Cerambycidae, Lamiinae, Hemilophini). Iheringia, Série Zoologia, (86): 77-116.

Galileo, M. H. M. \& U. R. Martins, 2001. Novas espécies de Lamiinae (Coleoptera, Cerambycidae) neotropicais. Iheringia, Série Zoologia, (90): 59-70.

Martins, U. R. \& M. H. M. Galileo, 1992. O gênero Hilaroleopsis Lane, 1970 e descrições de novos táxons em Hemilophini (Coleoptera, Cerambycidae, Lamiinae). Revista Brasileira de Entomologia 36(3): 589-596.

Monné, M. A. 1995. Catalogue of the Cerambycidae (Coleoptera) of the Western Hemisphere. Part XX. Subfamily Lamiinae: Tribos Hemilophini, Aerenicini, Pretiliini, Falsamblesthiini and Calliini. São Paulo, Sociedade Brasileira de Entomologia, $120 \mathrm{p}$.

Recebido em 19.II.2004; aceito em 20.VII.2004 